\title{
Causal relations between knowledge-intensive business services and regional employment growth
}

Citation for published version (APA):

Brenner, T., Capasso, M., Duschl, M., Frenken, K., \& Treibich, T. G. (2015). Causal relations between knowledge-intensive business services and regional employment growth. Maastricht University, Graduate School of Business and Economics. GSBE Research Memoranda No. 029 https://doi.org/10.26481/umagsb.2015029

Document status and date:

Published: 01/01/2015

DOI:

10.26481/umagsb.2015029

Document Version:

Publisher's PDF, also known as Version of record

\section{Please check the document version of this publication:}

- A submitted manuscript is the version of the article upon submission and before peer-review. There can be important differences between the submitted version and the official published version of record.

People interested in the research are advised to contact the author for the final version of the publication, or visit the DOI to the publisher's website.

- The final author version and the galley proof are versions of the publication after peer review.

- The final published version features the final layout of the paper including the volume, issue and page numbers.

Link to publication

\footnotetext{
General rights rights.

- You may freely distribute the URL identifying the publication in the public portal. please follow below link for the End User Agreement:

www.umlib.nl/taverne-license

Take down policy

If you believe that this document breaches copyright please contact us at:

repository@maastrichtuniversity.nl

providing details and we will investigate your claim.
}

Copyright and moral rights for the publications made accessible in the public portal are retained by the authors and/or other copyright owners and it is a condition of accessing publications that users recognise and abide by the legal requirements associated with these

- Users may download and print one copy of any publication from the public portal for the purpose of private study or research.

- You may not further distribute the material or use it for any profit-making activity or commercial gain

If the publication is distributed under the terms of Article $25 \mathrm{fa}$ of the Dutch Copyright Act, indicated by the "Taverne" license above, 
Thomas Brenner, Marco Capasso, Matthias Duschl, Koen Frenken, Tania Treibich

Causal Relations between Knowledge-Intensive Business Services and Regional Employment Growth

RM/15/029

\section{GSBE}

Maastricht University School of Business and Economics

Graduate School of Business and Economics

P.O Box 616

NL- 6200 MD Maastricht

The Netherlands 


\title{
Causal Relations between Knowledge-Intensive Business Services and Regional Employment Growth*
}

\author{
Thomas Brenner ${ }^{1}$, Marco Capasso ${ }^{2}$, Matthias Duschl ${ }^{1}$, Koen Frenken $^{3}$, and Tania \\ Treibich $^{2,4}$ \\ ${ }^{1}$ Department of Geography, Philipps University Marburg \\ ${ }^{2}$ School of Business and Economics, Maastricht University \\ ${ }^{3}$ Copernicus Institute, Utrecht University and CIRCLE, Lund University \\ ${ }^{4}$ OFCE and Scuola Superiore Sant'Anna
}

October 2, 2015

\begin{abstract}
This paper studies the causal relations between regional employment growth in KnowledgeIntensive Business Services (KIBS) and overall regional employment growth using German labour-market data for the period 1999-2012. Adopting a recently developed technique, we are able to estimate a structural vector autoregressive model in which the causal directions between KIBS and other sectors are examined including various time lags. One main finding holds that although regional growth has a negative short-term effect on KIBS, KIBS growth has a long-term positive effect on the whole regional economy. This result confirms the claim that KIBS can play a key role in regional policies. Distinguishing between financial and non-financial KIBS, we find that financial KIBS have a procyclical effect on regional growth underlining the potential de-stabilizing effect of a large financial sector.
\end{abstract}

JEL codes: C53, O33, R10

Keywords: Employment growth; growth spillovers; KIBS; industrial dynamics; financial geography.

${ }^{*}$ The authors would like to thank Giulio Bottazzi, Tom Broekel, Oliver Falck, Matthias Geissler, Alexandra Lopez Carmeno, Andrea Roventini and participants to the ENIC workshop in Halle and to the EMAEE 2015 conference in Maastricht for comments and suggestions. All the remaining errors are our own. 


\section{Introduction}

New global challenges call for more comprehensive research and innovation policies, relevant to all the sectors of the economy (Foray et al., 2009). Increasingly, the emphasis lies on policies that foster an entrepreneurial process of discovery: entrepreneurs should be enabled to discover the research and innovation domains in which a region can hope to excel, by gathering localized information about the region's skills, materials, environmental conditions, and market access conditions (Foray et al., 2009; McCann and Ortega-Argilés, 2013). Service innovation (coming from either services or manufacturing sectors) can boost entrepreneurial dynamism, by closing the gap between scientific innovation and market requirements, and facilitating a cross-sectoral fertilization which ultimately contributes to growth and jobs (European Commission, 2012). Inherent difficulties in supporting novelty creation in the form of services rather than goods (Rubalcaba et al., 2012; Janssen, 2014) may explain why in the European Union only a few countries have implemented policies explicitly focused on the service sectors (European Commission, 2009). Yet it remains unclear whether selecting target sectors may contribute to overall economic growth, let alone which sectors should receive most attention from policymakers. Additional empirical evidence on causal relations between sectoral employment growth dynamics is needed to address this issue.

Service sectors may occupy key positions in the network of inter-sectoral knowledge flows. Notably, knowledge-intensive business services (henceforth: KIBS) are able to provide advanced technological knowledge directly to other industrial sectors, and indirectly to the whole economy (Castellacci, 2008). Business service industries can be defined as KIBS if they are private organisations that rely heavily on professional knowledge, and supply intermediate products and services that are knowledge-based (Miles et al., 1995; Den Hertog, 2000). The process of "knowledge re-engineering" operated by the KIBS when interacting with other enterprises, and in particular with small and medium ones, causes KIBS to be a "relevant object" for both innovation and regional policies (Muller and Zenker, 2001). Still, the peculiarity of such process of knowledge creation has often prevented researchers from obtaining a precise evaluation of the innovative contribution of KIBS (Muller and Doloreux, 2009). Also for what concerns the impact of KIBS on growth (either at regional or at national level), there is no conclusive evidence in the literature (Rubalcaba, 2011). Because KIBS are attracted to places where they find demand and labour (Keeble and Nachum, 2002; Koch and Stahlecker, 2006; Jacobs et al., 2014; Herstad and Ebersberger, 2014), some authors argue that public policy should not be aimed directly at KIBS growth, but rather at fostering regional diversification and technological upgrading which in turn would drive KIBS growth through a demand-pull process (Wernerheim and Sharpe, 2003; Meliciani and Savona, 2015).

Research is needed to further investigate the system-wide interactions of KIBS, and to assess how different typologies of KIBS and manufacturing segments interact (Corrocher and Cusmano, 2014). This study investigates the causal relations between regional employment growth in the 
KIBS sector and regional employment growth in the rest of the economy. By means of a recent development of the Vector Auto Regression (VAR) approach, we are able to investigate empirically the causal effects of employment changes in KIBS and the rest of the economy on each other, as well as the time lags at which these feedbacks take place. In doing so, we would learn from the causal impact of past exogenous shocks what would be the expected impact of a (future) policy shock. The analysis is conducted over 270 labour market regions in Germany, observed between years 1999 and 2012 .

Section 2 discusses the mechanisms linking the dynamics of the KIBS sector to the rest of the economy. Section 3 explains the methodology used, and the reasons for adopting it. Section 4 describes the data. Section 5 shows the results and Section 6 concludes.

\section{Hypotheses}

\subsection{Feedback effects between KIBS and the rest of the economy}

It is often conjectured that future urban employment will be increasingly dependent on KIBS (Wood, 2006). The geographic distribution of KIBS is generally not more concentrated than other economic branches (Merino and Rubalcaba, 2013) but, at the same time, shows abnormally high values in some cities (Bryson et al., 2004). This could be explained by the tendency of KIBS to co-locate with multinational enterprises (Jacobs et al., 2014) in global cities (Sassen, 1991) and, in general, to rely on resources available externally (Herstad and Ebersberger, 2014). Especially in the early stages after foundation, KIBS benefit from their proximity to suppliers and clients (Koch and Stahlecker, 2006) and, in general, both demand-side influences and localized "collective learning" processes seem to determine the clustering of KIBS firms (Keeble and Nachum, 2002). Indeed, their activities are often associated to face-to-face interactions (McCann and Ortega-Argilés, 2013): the knowledge generated by the KIBS stems from interactive learning with a diverse set of economic actors. Yet, the economy can benefit collectively of the knowledge produced by KIBS even in the absence of bilateral connections among them, as their knowledge is diffused throughout the economy (Leiponen, 2001; Jensen et al., 2007). As a consequence, the contribution of KIBS to the productivity of the other industrial sectors may well exceed the productivity gains as measured within the KIBS sector itself (Castaldi, 2009). Such feedback effects can be rephrased in terms of the following hypotheses:

$\boldsymbol{H} 1$ (Knowledge diffusion): KIBS growth causes growth of the rest of the economy through its positive impact on productivity.

H2 (Demand-pull): Growth in the rest of the economy causes KIBS to grow by increasing the demand for their services. 


\subsection{KIBS, Manufacturing and Services}

The impact of KIBS on the local economy goes well beyond its contribution through the growth effects of knowledge diffusion and productivity growth, which we may reckon can be only observed after a certain delay. Indeed, another channel, more evident in the short-run, has been put forward by Moretti (2010) and Moretti and Thulin (2013). Their results imply that a growth in high-skilled labour-intensive activities stimulates the local economy by creating demand, especially in the non-tradable sector (i.e. services locally produced and consumed). They call this effect a "local multiplier" which can be understood as a "pecuniary externality":

"This multiplier effect stems from increases in the demand for local services generated by the increase in total earnings in the traded sector. As the number and wages of, say, manufacturing workers increases in a city, their demand for services like haircuts, restaurant meals, and medical care increases, thus raising the demand for hair stylists, waiters, and doctors in the city."(Moretti and Thulin, 2013, p. 339)

Although they focus on the impact of the tradable sector on local services (in order to explain why local governments subsidize the arrival of large new manufacturing firms, e.g. from the automobile industry), we may expect, from the same mechanism, that KIBS growth would also foster the demand for local services. Indeed, the magnitude of the "local multiplier" is "particularly large for employers with many well-educated workers and for employers in the high-technology sector"(Moretti and Thulin, 2013, p. 342). This leads us to formulate the following hypothesis:

H3 (Local multiplier): In the short-run, we expect growth in the KIBS sector to cause growth of other services, through the local multiplier effect.

Besides such link with other services, KIBS also co-evolve with the manufacturing sector. The first reason has to do with the role of KIBS in the development of (local) outsourcing of service activities (Fixler and Siegel, 1999; Groshen and Potter, 2003; Heshmati, 2003; Ono, 2003; Miozzo and Grimshaw, 2005; Grimshaw and Miozzo, 2006; Arora and Forman, 2007; Henderson and Ono, 2008), sustaining the productivity growth in both the manufacturing and service sectors (Fixler and Siegel, 1999). The externalization of business services has generally tightened the links between the manufacturing and services industries (Castellacci, 2008; Corrocher and Cusmano, 2014):

"[A]n intense process of outsourcing has taken place in recent decades, where many activities previously performed within manufacturing firms are now carried out by specialized business services. This process is leading to an increasing interdependence and a more intense knowledge exchange between manufacturing and service activities" (Castellacci, 2008, p.981). 
What are the implications of such interdependence on employment patterns across KIBS and manufacturing sectors? Heshmati (2003) explains that the impact of outsourcing on the increase in the labor share of services is due to its direct effect on workers' displacement as well as its indirect effect on the demand for services. In the case of KIBS, clients retain minimum "in-house" capabilities allowing them to keep interacting with the external supplier in close proximity (Miozzo and Grimshaw, 2005). This requires the outsourcing to be done in the local context (Ono, 2003; Miozzo and Grimshaw, 2005; Grimshaw and Miozzo, 2006; Henderson and Ono, 2008). Thus, we might infer that hypotheses 1 and 2 are all the more true when considering manufacturing sectors only: they should exert a demand-pull effect on KIBS, and the knowledge created by KIBS should spill more easily onto manufacturing firms due to outsourcing. In turn, the "displacement effect" mentioned by Heshmati (2003) can be explained by the fact that, in the short-run, local economies are limited in their availability of specialized labour: growing sectors drain their new employees from other industries. An increase in the activities and turnover of KIBS may require an increase in their number of employees, and such increase may be possible only through a decrease of employment in other sectors of the economy. A similar negative relation would operate also in the opposite direction: an increase in employment of the manufacturing sector, possibly due to integration of activities, might require the shift of specialized labour from the KIBS. In general, we can expect the following:

H4 (Labour Sharing): We expect that in the short-term, KIBS and the manufacturing sector would drain labour resources away from each other, corresponding to a negative relation.

Since our main research question relates to the interrelations between the KIBS sector and the rest of the economy, KIBS' internal diversity may matter as well.

\subsection{The different faces of KIBS}

While financial aspects of economic geographies have been neglected for a long time because "the prevailing notion was that financial markets are somehow separate from the real economy" (Lee et al., 2009, p. 726), more recent works have studied the geographical characteristics of financial activities (Coval and Moskowitz, 1999, 2001; Pike and Pollard, 2010). Pike and Pollard (2010) have pushed for considering financial activities as an "integral" element of our economic geographies. Their framing of the interrelation of financial activities and the real sector is quite negative, one reason being the risks such financialization puts on the real economy, due to the high procyclicality of their activities, thus accentuating the volatility of the business cycle.

By revealing the existence of a "local bias" in investors' portfolio, Coval and Moskowitz (1999) have shown that geography also matters when it comes to financial decisions. ${ }^{1}$ Such bias is due to the existence of asymmetric information between equity buyers and sellers, which can

\footnotetext{
${ }^{1}$ Klagge and Martin (2005) have confirmed the local bias in the case of venture capital firms in Germany.
} 
be best overcome by acquiring 'soft' information about companies. ${ }^{2}$ This type of information, yielding abnormal returns, requires proximity (Coval and Moskowitz, 2001). The importance of (short) distance to the acquisition of soft information has been much studied in the banking literature (Petersen and Rajan, 2002; Degryse and Ongena, 2005; Agarwal and Hauswald, 2010). Because their access to lending depends on a close relationship with their bank, small and young businesses are especially captive of local banks. Indeed, only close monitoring allows lenders to overcome these firms' opacity and lack of credit record (Degryse and Ongena, 2005). The importance of local banks to regional dynamics is all the more prevalent in decentralized financial systems such as in Germany (Klagge and Martin, 2005). Its "three-pillar" banking system groups universal banks into private banks, public banks or cooperative banks, of which both the public and cooperative ones have highly localized activities. Because of the prevalence of small-and-medium firms (the "Mittelstand") with poor access to external capital markets, local credit dominates the German financial system (Stolz and Wedow, 2011). This leads us to formulate our last hypothesis:

H5 (Financial vs. non-financial KIBS): We expect the impact of financial KIBS on the rest of the local economy to be larger than that of non-financial KIBS.

Summarizing our hypotheses, we could expect in the short-run either that KIBS growth leads to growth in services (H3: Local multiplier) or that the rest of the economy (especially manufacturing) negatively impacts KIBS growth due to H4 (Labour sharing). Instead, with some delay, we should observe a positive feedback effect from KIBS to the rest of the economy (H1: Knowledge diffusion) and back (H2: Demand-pull). Finally, we anticipate differences in the impact of financial and non-financial KIBS on the rest of the economy (H5).

\section{Methodology}

There are two variables of interest in our benchmark model, before proceeding to further disaggregation: regional employment growth in KIBS, and regional employment growth in the rest of the economy (i.e. in all the other industrial sectors, considered altogether). The goal of this study is determining how changes in one variable of interest, like a policy action which suddenly changes the employment growth in KIBS or in the rest of the economy, influences the evolution over time of both variables. The two variables of interest are endogenous: they influence each other, although we do not know to what extent nor over which time frame, as discussed in the previous section.

We denote by $y_{t}$ the vector containing the two variables of interest, as observed in year $t$. We assume that the whole regional economic system evolves in reaction to some exogenous

\footnotetext{
${ }^{2}$ Soft information is opposed to 'hard' information which is easily codifiable and can be found in firms' financial statements and credit records.
} 
events. These events are assumed to be drawn from a zero-mean probability distribution, and to be temporally uncorrelated; contemporaneous events are independent. In the literature on the VAR method these effects are called shocks and we use this language in the methodological part, calling changes that are triggered from exogenous events shocks. We denote by $\epsilon_{t}$ the vector of shocks impacting the variables of interest in year $t$.

We assume that the development of the regional economic system, independently of the sign and size of the shocks, can be described by the following Vector AutoRegression (VAR):

$$
y_{t}=B y_{t}+\Gamma_{1} y_{t-1}+\ldots+\Gamma_{p} y_{t-p}+\epsilon_{t}
$$

where the number of lags $p$ will be selected according to several information criteria, as explained in the next section. Equation (1) shows the dynamics of the regional economic system that we assume "structural" with respect to interventions on the shocks, and thus allows to predict the behavior of the variables of interest following the exogenous events (Hurwicz, 1962). The economic system evolves according to a law connecting the current growth of KIBS and of the rest of the economy (the vector $y_{t}$ on the left side of the equation) to its past values (the vectors $y_{t-1}, y_{t-2}, \ldots, y_{t-p}$ ) through the parameters $\Gamma$. Current growth of KIBS and of the rest of the economy is also connected to the current exogenous shocks $\epsilon_{t}$, and to itself through the matrix parameter $B$. Indeed, there are contemporaneous relations among the variables of interest, by which a shock to one variable may affect another variable "instantaneously" (within one time unit, i.e. within one year). ${ }^{3}$

Notice that, in Equation (1), all the information about past shocks is not explicitly shown, but is instead embodied in the values $y_{t-1}, y_{t-2}, \ldots, y_{t-p}$. In economic terms, that means: if we know the growth of KIBS and of the rest of the economy in the past, we do not need to reconstruct the whole history of previous exogenous shocks (i.e. why in the past the system evolved in that way) in order to understand what will happen to the economy this year, but we only need to know the new shocks $\epsilon_{t}$. Of course, the economic situation of one year ago or two years ago resulted in turn from other previous exogenous shocks. Under a stability condition (see Luetkepohl, 2009), we can easily represent the same model of Equation (1) as a moving average (Wold, 1938):

$$
y_{t}=\Psi_{0} \epsilon_{t}+\Psi_{1} \epsilon_{t-1}+\ldots+\Psi_{\infty} \epsilon_{t-\infty}
$$

where the economic situation of today is explicitly shown to depend on the whole history of exogenous shocks occurred in the past. $\Psi$ are the parameters connecting shocks and variables of interest, i.e. the "impulse responses" we want to estimate in order to assess the consequences that exogenous shocks have over time. The information about the past shocks $\epsilon_{1}, \epsilon_{2}, \ldots, \epsilon_{t}$, that

\footnotetext{
${ }^{3}$ In the final part of this section, we will explain why the existence of (almost) instantaneous relations among the variables of interest (in our case: of fast spillovers from KIBS growth to the other industries' growth, or vice versa) is an important issue that often prevents from a proper estimation of the structural form of the model.
} 
was shown in Equation (1), as embodied in the past values of $y$, is now explicitly expressed in terms of all previous exogenous shocks that in the past have hit the variables of interest, i.e. all shocks (including policy actions) that have shaped the evolution of the KIBS sector and of the rest of the economy. In order to assess the possible outcome of, e.g., future policies, we want to know the impulse responses $\Psi$, as in Equation (2).

The representation in Equation (2) is easy to obtain when knowing the "structural" form of the model as in Equation (1). However, estimating the "structural" form is not straightforward, because of the presence of contemporaneous effects as indicated by the parameter $B$ in Equation (1); instead, a vector autoregression in the "reduced form"

$$
y_{t}=A_{1} y_{t-1}+\ldots+A_{p} y_{t-p}+u_{t}
$$

can be easily estimated (Stock and Watson, 2001). The reduced form (Equation 3) would be structural only if there were no contemporaneous causal relations among the variables of interest, i.e. assuming that the matrix $B$ in Equation (1) is composed only of zeroes. If this is not the case, estimating the reduced form of Equation (3) cannot help to define the effects of an exogenous event (Sargent, 1979; Sims, 1986).

Indeed, there are many values of the parameters of Equation (1) that are consistent with estimates of Equation (3), and additional assumptions are needed to identify a preferred set of values. This "identifiability" problem has driven the research on structural vector autoregressions over the last three decades (see Stock and Watson, 2001, for a short summary and Hashimzade and Thornton, 2013, for a detailed survey). The main strands of research have focused on searching for plausible additional assumptions drawn from economic theory. The assumptions might concern the causal ordering, that is the short-term spillovers of the shocks (in our case, for instance, deciding a priori that KIBS affects the rest of the economy within one year, but not vice versa) or the long-term effects of the shocks (in our case, for instance, deciding a priori that a shock to KIBS does not influence regional growth in the long run, while a shock to the rest of the economy does). However, as argued in Section 2, there are no clear theoretical predictions about the direction of the contemporaneous or long-term relations between the growth of KIBS and of the rest of the economy.

Recent developments in the econometric research on structural vector autoregressions, coupled with recent empirical findings about regional dynamics, enable us to avoid imposing strong a priori causal ordering. The developments to which we refer, brought to the attention of the economic research community by Moneta et al. (2013), are based upon a deeper investigation of what the assumption of independence of the exogenous shocks ( $\epsilon_{t}$ in Equation 1$)$ entails.

Retrieving the structural form (1) from the estimated reduced form (3) means also retrieving the current and past exogenous shocks $\left(\epsilon_{t}, \epsilon_{t-1}\right.$ etc.) from the current and past residuals of the reduced-form estimation residuals $\left(u_{t}, u_{t-1}\right.$ etc.). In algebraic terms, this is equivalent to finding a rotation of the residual matrix which can be a possible structural shock matrix, i.e. a 
rotation of the residual matrix that is consistent with the assumptions about structural shocks. Traditionally, a way to consider a rotation of the residuals as a candidate for being the matrix of structural shocks is checking the correlation of its elements. However, the independence assumed for our model's shocks is a more restrictive concept than uncorrelatedness (lack of correlation is a necessary but not sufficient condition for independence). Therefore, the number of rotations, of the reduced-form residuals, which are characterized by independence is lower than the number of rotations which are characterized by uncorrelatedness. A deeper investigation of the independence property of the shocks allows to decrease the number of matrices that are potential candidates for representing the structural shocks $\left(\epsilon_{t}, \epsilon_{t-1}\right.$ etc. $)$, and thus to decrease the number of additional assumptions needed to choose among those candidates. Finding the rotations that have the independence property is known, in the signal processing literature, as "independent component analysis": if we assume that all exogenous shocks, or all shocks but one, are not only independent but also non-Gaussian, then it is possible to retrieve them from an observable rotation of them, that is, in our case, from the reduced-form estimation residuals (Comon, 1994; Hyvärinen and Oja, 2000).

Can we assume, in our context, that the exogenous shocks are non-Gaussian? We employ the same data set for which Duschl and Brenner (2013a) have observed a non-Gaussian (almost Laplacian) distribution of regional industry-specific employment growth rates (the data will be described in the next section). This finding can be connected to previous studies which found heavier-than-Gaussian tails in the empirical distributions of firm (sales and employment) growth rates (Stanley et al., 1996; Bottazzi et al., 2011), of industry (value added) growth rates (Castaldi and Sapio, 2008) and of country (aggregate output) growth rates (Fagiolo et al., 2008). NonGaussian distributions might in principle result from a stochastic process governed by Gaussian shocks (Brock, 1999). However, when the dependent variable of a linear model is characterized by a fat-tailed distribution (resembling a Laplace, or Exponential Power distribution), it is common practice to assume that the shocks are drawn from a similar distribution, and consequently to estimate the model by Least Absolute Deviation (LAD) regressions rather than by ordinary least squares (see e.g. Coad, 2010; Coad and Broekel, 2012). Non-Gaussianity of errors can thus be considered a reasonable assumption also for a model explaining industry growth rates at regional level.

The assumptions of independence and of non-Gaussianity of the shocks are not sufficient to identify the structural form (1); we need the third assumption that there is no contemporaneous feedback among the variables, which Moneta et al. (2013) refer to as the "acyclicality" assumption. It must be interpreted as follows: if, in our model, an exogenous shock to one variable is immediately able (within one time-unit, that is within one year in our context) to affect a second variable, then it is not possible that an exogenous shock to the second variable is immediately able to affect the first variable. Notice that there is no need to define a priori the ordering of the variables in the described causal structure. The Vector Auto-Regression Linear Non-Gaussian 
Acyclic Model (VAR-LiNGAM) algorithm (Shimizu et al., 2006; Hyvärinen et al., 2008), which we employ in this research, will define through a data-driven procedure whether a shock to KIBS is able to immediately affect the rest of the economy, or the other way around. The acyclicality is imposed only for the same time period in which the shock hits the economy, and the acyclic ordering is supposed to be constant over time: the immediate inter-sectoral propagation of the shock always goes in the same direction. However, the non-immediate propagation, that is the inter-sectoral spillover happening with a time lag equal or higher than one, is not restricted: the effect of any shock occurred in a given year (no matter whether the shock originated in the KIBS sectors or in other industries) can in principle propagate over the whole economy during the following years, and possibly generates cycles of growth across different sectors. ${ }^{4}$

\section{Data and variables}

Our data cover 270 labour market regions observed in Germany between years 1999 and 2012 . They result from the aggregation over the 413 German NUTS3 districts, and are in accordance with commuting flows (Binder and Schwengler, 2006). Moreover, labour market regions have been argued to be the adequate regional dimension in the context of innovation processes (Broekel and Binder, 2007). In particular, the 270 German labour market regions have already been used as geographical units for the estimation of a vector autoregression having regional employment growth as a variable of interest (Buerger et al., 2012).

We adopt the empirical classification in Jacobs et al. (2014), in turn based on the theoretical considerations by Strambach (2008), to define the KIBS sectors according to their NACE (Rev. 2 ) industry code (see Table 1). According to this classification, the financial organizations are considered as KIBS. Part of the literature shares the same view (e.g. Wood, 2006), while other studies prefer to adopt a more restrictive definition of KIBS (e.g. Koch and Stahlecker, 2006). To account for potential differences in their interaction with the regional economy, thus testing our last hypothesis (H5: Financial vs. non-financial KIBS), we also consider financial KIBS and non-financial KIBS separately (see Table 1). Unfortunately, given the amount of data available, the model estimation is not possible when the variables of interest are more than two. Therefore, we will estimate separate models in which, in turn, the "KIBS" variable of interest refers to all the KIBS, or only to the financial KIBS, or only to the non-financial KIBS.

Analogously, the peculiar relations observed between KIBS and manufacturing sectors (e.g. Corrocher and Cusmano, 2014) bring us to estimate two models having, as a second variable of interest opposed to KIBS, respectively manufacturing and service sectors. Indeed, as discussed in Section 2, the Local multiplier (H3), and Labour sharing (H4) effects imply a particular

\footnotetext{
${ }^{4}$ Details about the VARLiNGAM estimation algorithm can be found in Hyvärinen et al. (2008). Pioneering applications of the algorithm to economic fields have involved macroeconomics (Moneta et al., 2013), happiness economics (Coad and Binder, 2014), energy economics (Ferkingstad et al., 2011), firm dynamics (Moneta et al., 2013; Coad et al., 2012), and regional dynamics (Duschl and Brenner, 2013b).
} 
Table 1: Definition of KIBS in terms of NACE industry classification

\begin{tabular}{lll}
\hline KIBS & NACE & Description \\
category & & \\
\hline \multirow{2}{*}{$\begin{array}{l}\text { Financial } \\
\text { KIBS }\end{array}$} & 64.1 & Monetary intermediation \\
& 64.2 & Activities of holding companies \\
& 64.3 & Trusts, funds and similar financial entities \\
& 64.9 & Other financial services activities, except insurance and pension funding \\
& 66.1 .1 & Administration of financial markets \\
Non-financial & 69.2 & Accounting, bookkeeping and auditing activities; tax consultancy \\
& 62.0 .1 & Computer programming activities \\
& 62.0 .2 & Computer consultancy activities \\
& 70.1 & Activities of head offices \\
& 70.2 & Management consultancy services \\
& 73.1 & Advertising \\
& 73.2 & Market research and public opinion polling \\
& 72.1 & Research \& experimental development on natural sciences and engineering \\
& 72.2 & Research \& experimental development on social sciences and humanities \\
& & \\
\hline
\end{tabular}

relation between KIBS and other services or manufacturing sectors. We consider as services all sectors having the following 2-digit NACE codes: 33; 45 to 82; and 90 to 96 (for our analysis, we exclude from this list the sectors that we consider as KIBS, to avoid double counting). ${ }^{5}$

Summing up, we have six variables divided into a set of three variables associated to KIBS (all KIBS, only financial KIBS, only non-financial KIBS), and a set of three variables associated to the rest of the economy (all non-KIBS sectors, only manufacturing, only non-KIBS services). We will estimate nine models, each one considering, as variables of interest, only one variable from the first (KIBS) set, and only one variable from the second (rest of the economy) set. Said in terms of the notation in Equation (1), there are always only two elements constituting the vector $y_{t}$. See Table 2 for a summary of each model in terms of its variables of interest.

To construct the six variables, our starting point is the regional employment level (which we denote by $x_{t}$ ) associated to each of the variables. The second column of Table 3 shows the mean and standard deviations, computed across regions and across years, of the employment level respectively for the six variables. Then, we compute the regional employment growth rates $g_{t}$ as log-differences of employment:

$$
g_{t}=\log \left(x_{t}\right)-\log \left(x_{t-1}\right)
$$

\footnotetext{
${ }^{5}$ The rationale behind our NACE code list is the following. The OECD (the official OECD website: http://stats . oecd.org/glossary/detail . asp?ID=2435) does not consider construction, nor energy, nor public administration sectors as part of the service sector. Castaldi (2009) excludes, from her analysis of intersectoral linkages, also education, health and social work "because, by responding only partially to market forces, they follow different patterns of competition and growth". Because of similar reasons (building of waste disposal plants, which can involve mainly construction and manufacturing processes; partial dependence on state control) we also exclude the sectors related to water supply, sewages and waste management from our services NACE list.
} 
Table 2: Summary of the nine models.

\begin{tabular}{lccc}
\hline & All KIBS & $\begin{array}{c}\text { Financial } \\
\text { KIBS }\end{array}$ & $\begin{array}{c}\text { Non-financial } \\
\text { KIBS }\end{array}$ \\
\hline All the other (non-KIBS) sectors & Model 1 & Model 2 & Model 3 \\
Manufacturing sectors & Model 4 & Model 5 & Model 6 \\
Other (non-KIBS) service sectors & Model 7 & Model 8 & Model 9 \\
\hline $\begin{array}{l}\text { Note. Column labels indicate the first variable of interest, i.e. the first element of } \\
y_{t} \text { in Equation 1; row labels indicate the second variable of interest, i.e. the second } \\
\text { element of } y_{t} \text { in Equation 1. }\end{array}$
\end{tabular}

We cannot directly feed the growth rates $g_{t}$ to our estimation algorithm, because of a negative relation between the levels of the region-industry employment, and the variance of their growth rates (Duschl and Brenner, 2013a). Such "variance scaling" relation is well-known in industrial dynamics: the lower is the firm size, the higher is the variance of its growth rate (Stanley et al., 1996). This empirical law seems to hold also for regional dynamics, and cannot be ignored when modeling growth rates, because the heteroscedasticity generated by the law can bias the estimation (Bottazzi et al., 2014). Duschl and Brenner (2013a) show that the problem can be circumvented by an appropriate rescaling of the growth rates, based on the estimation of the variance scaling parameters. We adopt the same procedure (for details, see Duschl and Brenner, 2013a), and we obtain the rescaled growth rates which we will use as variables of interest in our model (i.e. as the elements of the vector denoted as $y_{t}$ in Equations 1, 2 and 3). For each of the six sectoral aggregations, corresponding to the six variables of interest, Table 3 reports descriptive statistics of both the not rescaled growth rates $\left(g_{t}\right)$ and the rescaled growth rates $\left(y_{t}\right)$. Henceforth, when referring simply to "growth", we will mean "rescaled growth".

Table 3: Descriptive statistics

\begin{tabular}{|c|c|c|c|c|c|c|}
\hline & \multirow{2}{*}{\multicolumn{2}{|c|}{ Employment level }} & \multicolumn{4}{|c|}{ Employment growth } \\
\hline & & & \multicolumn{2}{|c|}{ Not rescaled $\left(g_{t}\right)$} & \multicolumn{2}{|c|}{ Rescaled $\left(y_{t}\right)$} \\
\hline & Mean & s.d. & Mean & s.d. & Mean & s.d. \\
\hline All KIBS & 6542.8 & 16524.2 & -0.013 & 0.069 & -0.012 & 0.069 \\
\hline Financial KIBS & 3567.2 & 7994.8 & -0.003 & 0.044 & -0.003 & 0.044 \\
\hline Non-financial KIBS & 2975.6 & 8920.8 & 0.006 & 0.203 & 0.001 & 0.184 \\
\hline All other (non-KIBS) sectors & 92259.8 & 132782.4 & -0.002 & 0.018 & -0.002 & 0.017 \\
\hline Manufacturing & 23547.4 & 29303.8 & 0.003 & 0.034 & 0.002 & 0.033 \\
\hline Other (non-KIBS) services & 41396.2 & 72856.0 & -0.002 & 0.030 & -0.002 & 0.028 \\
\hline
\end{tabular}

In Figure 1, we show the empirical distribution of regional growth rates for, respectively, 
KIBS (left plot) and all the other sectors (right plot, pooling together the regional growth rates of all the yearly cross-sectional waves). With log frequency on the vertical axis, the distributions look clearly tent-shaped, thus confirming the finding by Duschl and Brenner (2013a) that the Laplace-like features of growth rate distributions can be retrieved also at regional level. ${ }^{6}$ As previously explained, this finding hints that non-Gaussian shocks are driving the dynamics of our data, an important prerequisite for the estimation of the structural form of the models.

Figure 1: Growth rate distributions. Left: Growth of KIBS; right: Growth in all the other sectors.
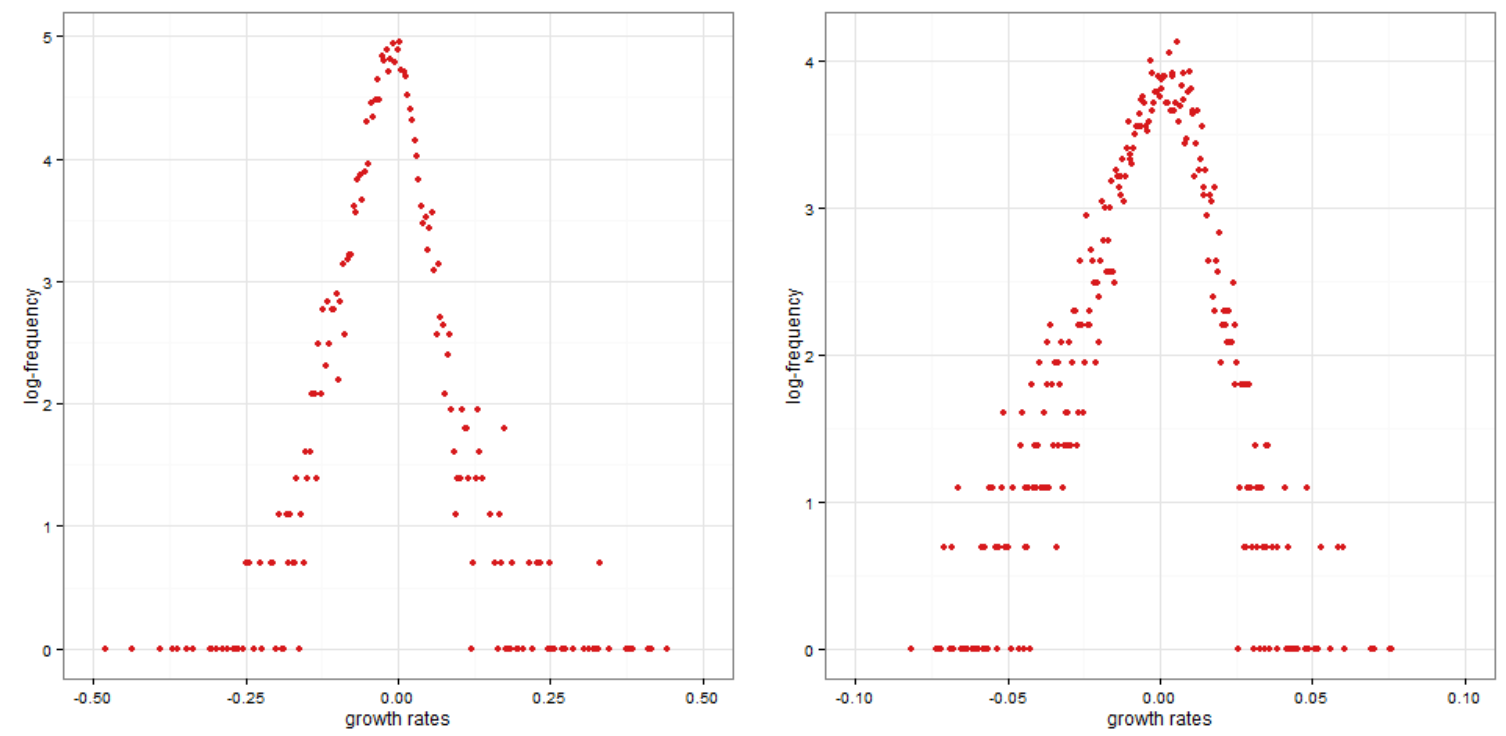

There are other variables that influence the variables of interest, and are not influenced by them: they are assumed to be exogenous to our model, and we control for them. Such control variables are measured only at the initial time of our dataset (later observation might invalidate the exogeneity assumption) and are: population density, share of KIBS employment over total employment, and a dummy variable equal to 1 if the region belongs to the former East Germany (and zero otherwise). Although we do not report the statistics and estimations relative to them, the control variables are always included in our models.

The selection of the number of lags $p$ in the vector autoregression is based on various statistics, like the Akaike Information, the Hannan-Quinn or the Schwarz Criterion (Lütkepohl, 2001). Here, all criteria advocate a 1-lag model, which is driven by the disproportionate loss of information that is not counterbalanced by additional explanatory power from the inclusion of further lags. Because the selection of lag length might statistically collide with the determination of the causal ordering (Demiralp and Hoover, 2003), we checked whether the latter stays robust when

\footnotetext{
${ }^{6}$ For all the other variables we consider, the empirical growth distributions (not shown here) display similar features.
} 
increasing the number of lags. No changes in the causal ordering are observed and the estimates remain very similar in a 2-year lag model.

\section{Results}

For each model, we present our results in two forms. Tables 4 to 6 will show the parameter estimates for the structural autoregressive form of the model, as in Equation (1). Figures 2 to 4 will illustrate the evolution of the variables of interest over time, following a shock applied to one of them.

In the tables, each estimated coefficient must be interpreted as measuring the effect of the row variable on the column variable. The estimates of the instantaneous spillovers (the spillovers occurring within one year, that is the elements of the matrix parameter $B$ of Equation 1) are, then, in the rows having, as label on the left column, the variables with the "(t)" suffix; while the estimates of the spillovers occurring at lag 1 (i.e. the spillovers $\Gamma_{1}$ occurring after one year) are in the rows having, as label on the left column, the variables with the "(t-1)" suffix.

We can trace the evolution of the variables of interest over time by, first, moving from the autoregressive representation (1) to the moving average representation (2) (i.e. from the autoregression parameters $B$ and $\Gamma$ to the impulse responses $\Psi$ ), and then by computing the cumulative sum of the impulse response function as:

$$
\Psi_{l}^{a}=\sum_{j=0}^{l} \Psi_{j}
$$

where $l$ indicates the number of time units (lags) after the shock impact. The "accumulated" impulse response function in Equation (5) is instrumental to answer our research question because of the complicated time structure of impulse responses in Equation (2). To explain why this is the case, we need to reflect, in economic terms, on the model representations in Equations (1) and (2). Having only one lag in the autoregressive representation (1) means that the level, this year, of a variable of interest, say of employment growth in KIBS, has an influence on next year's level of the other variable of interest, say of growth in the rest of the economy. But the growth of the rest of the economy next year will influence the growth of KIBS, and of the rest of the economy, the following year (i.e. in two years from now): an exogenous shock applied today to any variable can change the whole evolution of all the variables throughout all the following years. That is why, in the moving average representation of Equation (2), we see that the current growth rate of a variable depends on the exogenous shocks that occurred in the system in all the previous years. In order to understand the overall effect on the rest of the economy, after five years, of a shock to KIBS that occurred today, we need to sum all the effects that today's shock will have year after year: we need the accumulated impulse response function of Equation (5). ${ }^{7}$

\footnotetext{
${ }^{7}$ We do not show any graphs of the accumulated response of a variable to a shock on the same variable, since
} 
Table 4 shows the estimates of the parameters of the structural autoregression (Equation 1) when modelling KIBS growth versus growth in all the other sectors (i.e. versus rescaled growth of total regional employment minus KIBS employment). In particular, the top panel of Table 4 shows the estimates for Model 1, when not distinguishing between financial and non-financial KIBS. Because of the "acyclicality" assumption we impose, the VARLiNGAM algorithm has to choose the prevailing causality direction for instantaneous inter-sectoral diffusion. The causality direction goes from the rest of the economy to KIBS. Notably, the parameter estimation is negative (estimation value: -0.258): an increase in employment in the regional economy brings immediately a decrease in the employment in KIBS. This could be due to a labour-supply effect by which, in the very short term, employees move from KIBS firms to the rest of the economy, in accordance with hypothesis H4 (Labour sharing). Instead, hypothesis H3 (Local Multiplier) on the positive income effect of KIBS workers' high wages on the local economy is not corroborated by the evidence.

After one year, however, the picture is completely different: the growth in the rest of the economy calls for a higher demand of business services, which in turn translates into KIBS growth (parameter estimate: +0.381). This result is in line with hypothesis $\mathbf{H 2}$ (Demand-pull). Because we also observe a positive lagged effect of KIBS on the rest of the economy (parameter estimate: +0.024), as expected from hypothesis H1 (Knowledge diffusion), a positive feedback loop is set into motion.

To understand which effect prevails in the long run, we need to inspect the left panel of Figure 2(a), showing the accumulated response of KIBS growth (as a solid line) to a unit shock on the growth in the rest of the economy. The dashed lines in the figure delimit a $68 \%$ confidence interval. ${ }^{8}$ It appears that, after one year, KIBS are likely to recover from the initial negative impact, and after three years the cumulated effect becomes significantly positive.

The central and lower panels of Table 4 (where, respectively, only financial and only nonfinancial KIBS have been considered) show that the non-financial KIBS are the only ones experiencing the instantaneous negative repercussion (parameter estimate: -1.133). According to our explanation above, this means that labour sharing with the rest of the economy $(\mathbf{H} 4)$ mainly concerns non-financial service activities. It is also a first element corroborating our hypothesis H5 (Financial vs. non-financial KIBS). Indeed, financial KIBS experience a positive effect already during the first year of general growth in the region (parameter estimate: +0.130 ), although we are not able to discern whether the negative repercussion does not exist at all, or is simply overcompensated by a very fast increase in demand for financial expertise from the rest of the economy, as expected by $\mathbf{H 2}$ (Demand-pull). At this point, we need to remind the

\footnotetext{
the focus of our study is on growth spillovers across different industries.

${ }^{8}$ The $68 \%$ confidence interval is often used because of its comparability with the Gaussian case. When the distribution of the estimation errors is Gaussian, by adding (subtracting) exactly one standard deviation to (from) the mean estimation, the upper (lower) bound of the $68 \%$ confidence interval is obtained.
} 
Table 4: VARLiNGAM estimates of the parameters of the structural autoregression (1) when modelling KIBS growth versus growth in all the other sectors.

\begin{tabular}{|c|c|c|}
\hline dep var: & all KIBS (t) & $\begin{array}{l}\text { all other (non-KIBS) } \\
\text { sectors }(\mathrm{t})\end{array}$ \\
\hline \multirow[t]{2}{*}{ all KIBS (t) } & - & - \\
\hline & - & - \\
\hline \multirow[t]{2}{*}{ all other (non-KIBS) sectors (t) } & $-0.258^{*}$ & - \\
\hline & $(0.139)$ & - \\
\hline \multirow[t]{2}{*}{ all KIBS (t-1) } & 0.015 & $0.024^{* * *}$ \\
\hline & $(0.015)$ & $(0.005)$ \\
\hline \multirow[t]{2}{*}{ all other (non-KIBS) sectors $(\mathrm{t}-1)$} & $0.381^{* * *}$ & $0.391^{* * *}$ \\
\hline & $(0.079)$ & $(0.027)$ \\
\hline
\end{tabular}

Model 2: Financial KIBS vs all other (non-KIBS) sectors

\begin{tabular}{|c|c|c|}
\hline dep var: & fin. $\operatorname{KIBS}(\mathrm{t})$ & $\begin{array}{l}\text { all other (non-KIBS) } \\
\text { sectors }(\mathrm{t})\end{array}$ \\
\hline fin. KIBS (t) & - & - \\
\hline all other (non-KIBS) sectors (t) & $\begin{array}{l}- \\
0.130^{* * *} \\
(0.050)\end{array}$ & $\begin{array}{l}- \\
- \\
-\end{array}$ \\
\hline fin. KIBS (t-1) & $\begin{array}{l}0.078^{* * *} \\
(0.021)\end{array}$ & $\begin{array}{l}0.027^{* * *} \\
(0.007)\end{array}$ \\
\hline all other (non-KIBS) sectors (t-1) & $\begin{array}{l}0.181^{* * *} \\
(0.046)\end{array}$ & $\begin{array}{l}0.395^{* * *} \\
(0.028)\end{array}$ \\
\hline
\end{tabular}

Model 3: Non-financial KIBS vs all other (non-KIBS) sectors

\begin{tabular}{lll} 
dep var: & non-fin. KIBS (t) & $\begin{array}{l}\text { all other (non-KIBS) } \\
\text { sectors }(\mathrm{t})\end{array}$ \\
\hline non-fin. KIBS (t) & - & - \\
all other (non-KIBS) sectors (t) & $-1.133^{* * *}$ & - \\
& $(0.350)$ & - \\
& & - \\
non-fin. KIBS (t-1) & 0.014 & $0.009^{* * *}$ \\
& $(0.012)$ & $(0.002)$ \\
all other (non-KIBS) sectors (t-1) & $0.763^{* * *}$ & $0.391^{* * *}$ \\
& $(0.189)$ & $(0.028)$
\end{tabular}

Notes. ${ }^{*} 10 \%$ significance; ${ }^{* *} 5 \%$ significance; $* * * 1 \%$ significance; bootstrapped standard errors in brackets. 
Table 5: VARLiNGAM estimates of the parameters of the structural autoregression (1) when modelling KIBS growth versus growth in the manufacturing sectors.

\begin{tabular}{lll} 
Model 4: All KIBS vs Manufacturing \\
dep var: & all KIBS (t) & Manufacturing (t) \\
\hline \multirow{2}{*}{ all KIBS (t) } & - & - \\
& - & - \\
Manufacturing (t) & $-0.298^{* * *}$ & - \\
& $(0.094)$ & - \\
& & \\
all KIBS (t-1) & 0.011 & 0.009 \\
& $(0.021)$ & $(0.011)$ \\
Manufacturing (t-1) & 0.056 & $0.247^{* * *}$ \\
& $(0.042)$ & $(0.027)$ \\
\hline
\end{tabular}

Model 5: Financial KIBS vs Manufacturing

\begin{tabular}{lll} 
dep var: & fin. KIBS (t) & Manufacturing (t) \\
\hline \multirow{2}{*}{ fin. KIBS (t) } & - & - \\
& - & - \\
Manufacturing (t) & -0.086 & - \\
& $(0.084)$ & - \\
& & \\
fin. KIBS (t-1) & $0.099^{* * *}$ & 0.008 \\
& $(0.022)$ & $(0.016)$ \\
Manufacturing (t-1) & 0.026 & $0.249^{* * *}$ \\
& $(0.028)$ & $(0.027)$ \\
\hline
\end{tabular}

Model 6: Non-financial KIBS vs Manufacturing

\begin{tabular}{|c|c|c|}
\hline dep var: & non-fin. KIBS (t) & Manufacturing (t) \\
\hline \multirow[t]{2}{*}{ non-fin. KIBS (t) } & - & - \\
\hline & - & - \\
\hline \multirow{2}{*}{ Manufacturing (t) } & $-0.508^{* * *}$ & - \\
\hline & $(0.160)$ & - \\
\hline \multirow[t]{2}{*}{ non-fin. KIBS (t-1) } & 0.005 & $0.008^{* *}$ \\
\hline & $(0.011)$ & $(0.004)$ \\
\hline \multirow[t]{2}{*}{ Manufacturing (t-1) } & $0.239 * * *$ & $0.249^{* * *}$ \\
\hline & $(0.073)$ & $(0.026)$ \\
\hline
\end{tabular}


Table 6: VARLiNGAM estimates of the parameters of the structural autoregression (1) when modelling KIBS growth versus growth in all the other service sectors.

Model 7: All KIBS vs all other (non-KIBS) service sectors

\begin{tabular}{lll} 
dep var: & all KIBS $(\mathrm{t})$ & $\begin{array}{l}\text { all other (non-KIBS) } \\
\text { service sectors }(\mathrm{t})\end{array}$ \\
\hline \multirow{2}{*}{ all KIBS (t) } & - & - \\
& - & - \\
all other (non-KIBS) service sectors (t) & 0.025 & - \\
& $(0.132)$ & - \\
& 0.019 & $0.035^{* * *}$ \\
all KIBS (t-1) & $(0.016)$ & $(0.009)$ \\
all other (non-KIBS) service sectors (t-1) & $0.132^{* * *}$ & $0.222^{* * *}$ \\
& $(0.048)$ & $(0.027)$ \\
\hline
\end{tabular}

Model 8: Financial KIBS vs all other (non-KIBS) service sectors

\begin{tabular}{|c|c|c|}
\hline dep var: & fin. KIBS (t) & $\begin{array}{l}\text { all other (non-KIBS) } \\
\text { service sectors }(\mathrm{t})\end{array}$ \\
\hline \multirow[t]{2}{*}{ fin. $\operatorname{KIBS}(\mathrm{t})$} & - & - \\
\hline & - & - \\
\hline \multirow[t]{2}{*}{ all other (non-KIBS) service sectors $(\mathrm{t})$} & $0.184^{* *}$ & - \\
\hline & $(0.080)$ & - \\
\hline \multirow[t]{2}{*}{ fin. $\operatorname{KIBS}(\mathrm{t}-1)$} & $0.075^{* * *}$ & $0.046^{* *}$ \\
\hline & $(0.021)$ & $(0.019)$ \\
\hline \multirow[t]{2}{*}{ all other (non-KIBS) service sectors (t-1) } & $0.067 * *$ & $0.212^{* * *}$ \\
\hline & $(0.030)$ & $(0.029)$ \\
\hline
\end{tabular}

Model 9: Non-financial KIBS vs all other (non-KIBS) service sectors

\begin{tabular}{lll} 
dep var: & non-fin. KIBS (t) & $\begin{array}{l}\text { all other (non-KIBS) } \\
\text { service sectors }(\mathrm{t})\end{array}$ \\
\hline \multirow{2}{*}{ non-fin. KIBS (t) } & - & - \\
all other (non-KIBS) service sectors (t) & -0.224 & - \\
& $(0.241)$ & - \\
& & - \\
non-fin. KIBS (t-1) & 0.006 & $0.011^{* * *}$ \\
& $(0.012)$ & $(0.003)$ \\
all other (non-KIBS) service sectors (t-1) & $0.290^{* * *}$ & $0.216^{* * *}$ \\
& $(0.103)$ & $(0.027)$
\end{tabular}

Notes. $^{*} 10 \%$ significance; ${ }^{* *} 5 \%$ significance; ${ }^{* * *} 1 \%$ significance;

bootstrapped standard errors in brackets. 
Figure 2: Cumulative impulse response functions when modelling KIBS growth versus growth in all the other sectors. The dashed lines delimit the $68 \%$ confidence intervals.
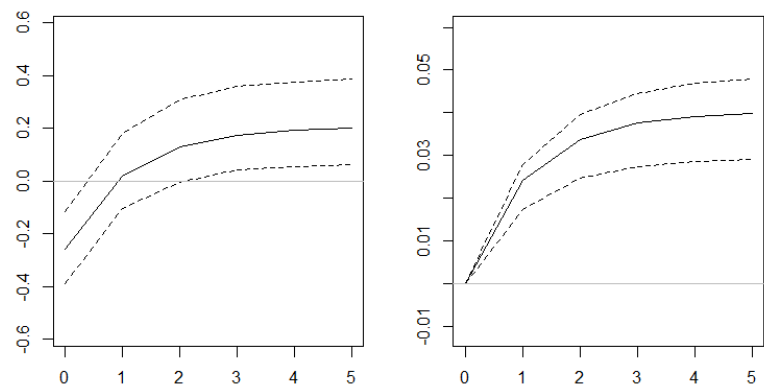

(a) Model 1 (All KIBS vs. all other (non-KIBS) sectors)
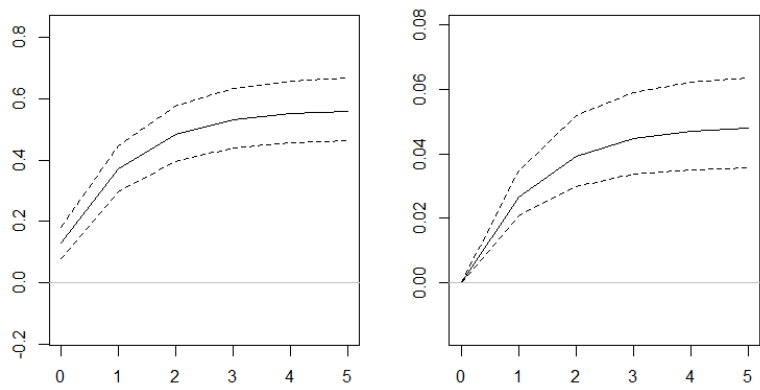

(b) Model 2 (Financial KIBS vs. all other (non-KIBS) sectors)
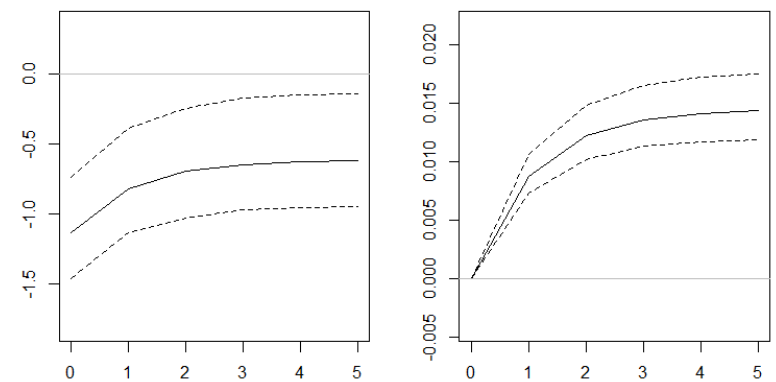

(c) Model 3 (Non-financial KIBS vs. all other (non-KIBS) sectors) 
Figure 3: Cumulative impulse response functions when modelling KIBS growth versus growth in the manufacturing sectors. The dashed lines delimit the $68 \%$ confidence intervals.
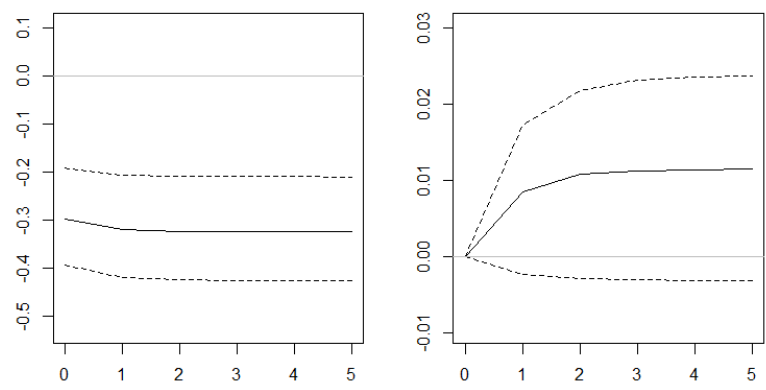

(a) Model 4 (All KIBS vs. Manufacturing)
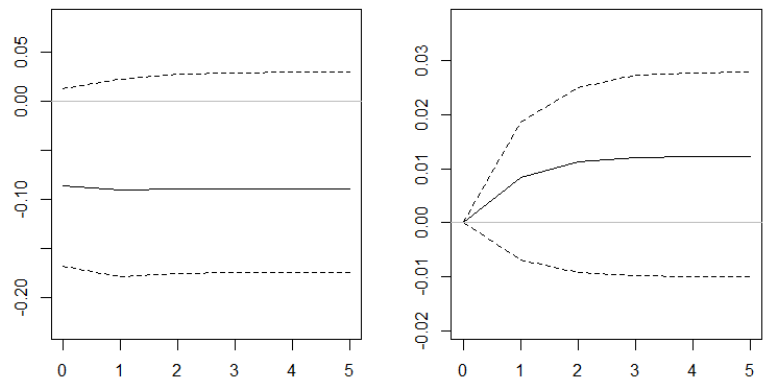

(b) Model 5 (Financial KIBS vs. Manufacturing)
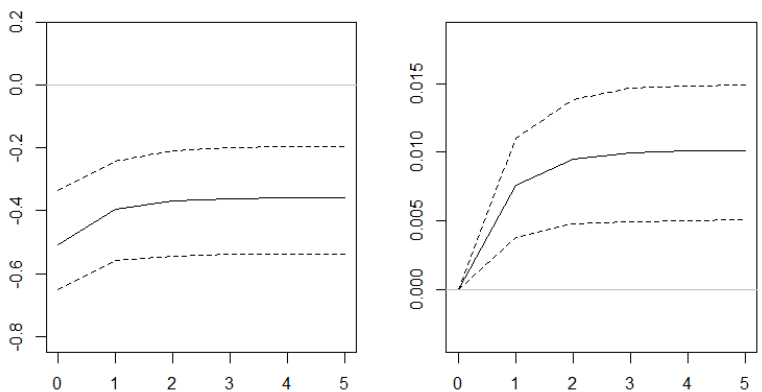

(c) Model 6 (Non-financial KIBS vs. Manufacturing) 
Figure 4: Cumulative impulse response functions when modelling KIBS growth versus growth in all the other service sectors. The dashed lines delimit the $68 \%$ confidence intervals.
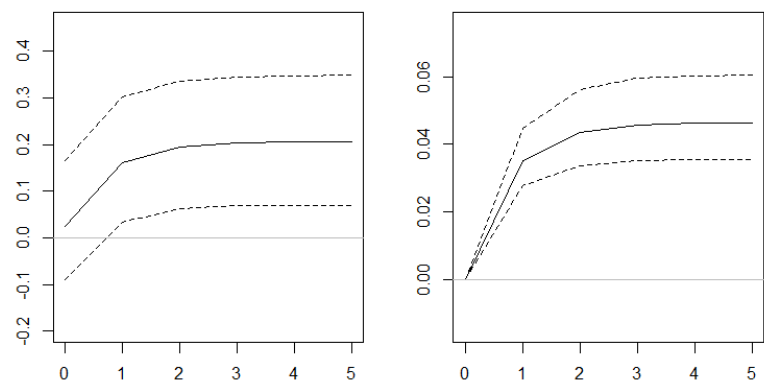

(a) Model 7 (All KIBS vs. all other (non-KIBS) service sectors)
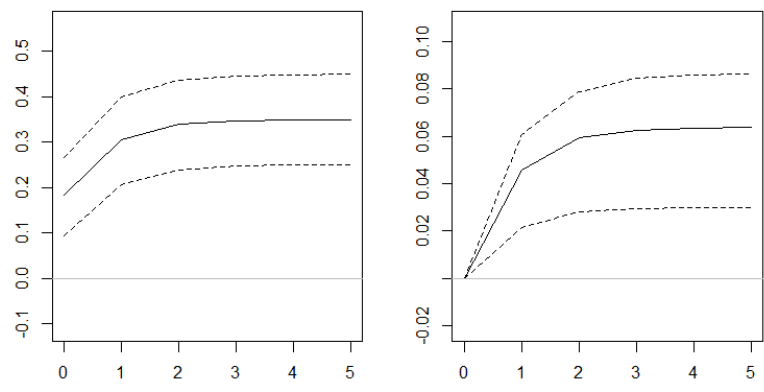

(b) Model 8 (Financial KIBS vs. all other (non-KIBS) service sectors)
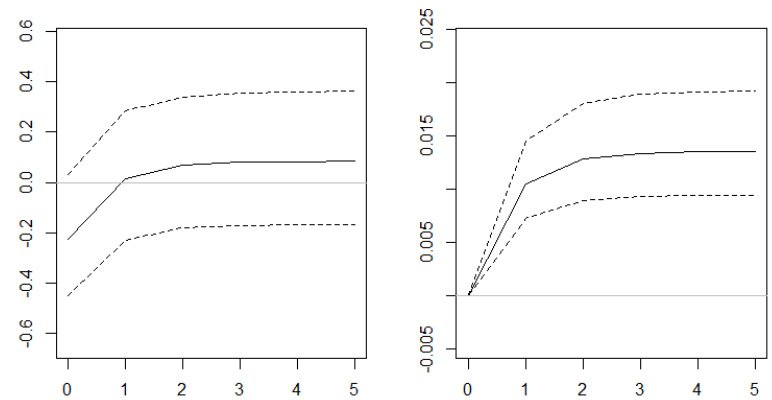

(c) Model 9 (Non-financial KIBS vs. all other (non-KIBS) service sectors) 
reader that the relations of our system, as modeled in Equation (1) and (2), are linear, and thus symmetric: a positive effect of a positive shock corresponds to a negative effect of a negative shock. In our tables, a positive estimated coefficient indicates a positive causal relation between variables, and also as a potential source of contagion to other industries of a crisis originated in one sector. In this sense, the fact that our results point toward a procyclical behavior of financial KIBS, i.e. the fact that financial KIBS seem to prosper during the good times of the economy, must be taken into account also when evaluating the potential impact of a crisis in the rest of the economy: financial KIBS are going to suffer already in the immediate aftermath of a bad event affecting the region.

The fact that hypothesis H4 (Labour sharing) only seems to be validated in the case of non-financial KIBS could be due to the reduced labour sharing opportunities between financial KIBS and the rest of the economy associated with a lower level of transferability of skills. Indeed, Neffke and Henning (2013) have shown that financial services are highly clustered in the periphery of the industry space, meaning they require highly specialized labour for which the skills are difficult to transfer to other sectors. In the case of Germany, Klagge and Martin (2005) qualify these specialized labour markets as "financial communities". Instead, business services (and by extension to our typology, non-financial KIBS) are positioned in a wide range of locations, thus sharing skills with many non-KIBS activities. ${ }^{9}$

The left panel of Figure 2(c) puts in evidence how non-financial KIBS may never fully recover from the negative impact, despite a positive feedback effect after a one-year delay, from non-financial KIBS to the rest of the economy $(+0.009$, third column of the bottom panel of Table 4) and from the rest of the economy to non-financial KIBS $(+0.763$, second column of the same table). Contributing to the "cycle" of growth connecting financial KIBS to the rest of the economy, there is the high positive estimate $(+0.027$, third column of the central panel of Table 4) of the parameter linking growth in the rest of the economy to the previous year's growth of financial KIBS, as well as from the rest of the economy to financial KIBS $(+0.181$, third column of the same table). Thus, the development of non-financial and financial KIBS in the following years as a response to an exogenously caused change in the rest of the economy are quite different.

The rest of the economy profits from growth in non-financial KIBS as well as from financial KIBS. So, in general, we can say that a positive exogenous shock on KIBS, although with some lag, creates employment growth in the rest of the economy, as also depicted in the right panels of Figures 2(b) and (c). We can now investigate whether the positive shock of KIBS spills over the whole economy indistinctly, or instead employment is created only in manufacturing or in service sectors.

The right columns of Table 5 show that the manufacturing sector seems to profit with a

\footnotetext{
${ }^{9}$ Such variety across KIBS sectors' occupational structures and skill requirements is in accordance with other contributions from the literature (Consoli and Elche-Hortelano, 2010).
} 
time lag of one year from growth in non-financial KIBS (+0.008), while financial KIBS do not significantly impact the manufacturing sector. When considering KIBS as a whole (top panel of Table 5), the manufacturing sector appears not to be significantly affected by growth in KIBS, while KIBS seem to be affected by positive manufacturing growth only negatively in the short-run. Indeed, the contemporaneous negative influence of manufacturing growth on KIBS is high (parameter estimate: -0.298), as a result of the strong negative effect on non-financial KIBS $(-0.508$, in the bottom panel of Table 5$)$ not compensated by any influence on financial KIBS (-0.086, not significant). This result is in line with our above argument on a higher skill-relatedness between non-financial KIBS and the rest of the economy than for financial KIBS.

After one year, there is a positive inter-relation between manufacturing and non-financial KIBS only, and no relation at all with regard to financial KIBS. This can be explained by the fact that relations between manufacturing sectors and non-financial KIBS have been recently made stronger by a higher intensity of outsourcing of non-financial service activities, such as cleaning and building management but also research, computer-related and marketing activities, by those manufacturing firms (see also Castellacci, 2008).

In Figure 3(b) the separation between the financial KIBS and the manufacturing sector is evident: none of the two variables experiences an appreciable effect of a shock to the other variable. The right panel of Figure 3(c), instead, shows that the manufacturing sector employment grows after a positive shock to non-financial KIBS.

Similarly, the rest of the service sector follows, with some lag, the growth in non-financial KIBS (+0.011, bottom panel of Table 6$)$, while, contrary to the manufacturing case, labour sharing between service sectors and non-financial KIBS is not observed ( -0.224 , not significant). Hence, its growth can reach higher levels (Figure 4(c), right panel). The interaction between financial KIBS and other service industries is strong (high and significant estimates in the central panel of Table 6), with financial KIBS experiencing an immediate growth spurt following a positive change in other services (Figure 4(b)).

Before concluding this paper, we implement as a robustness test a structural VAR which is estimated via ordinary least squares for all nine models. For the SVAR to be estimated we need only to impose that structural innovations are orthogonal, but normally distributed. We use as short-run restriction that the KIBS sector has no contemporaneous impact on the rest of the economy (the contemporaneous causal ordering is fixed ex-ante instead of being datadriven). This exercise is intended to confirm that imposing the causal ordering but weakening our assumption on the structure of shocks does not alter our findings. The results show that the signs and magnitudes of the coefficients are very similar to our initial results under this alternative methodology, giving breadth to our findings. 


\section{Conclusion}

Using a new statistical technique, we have been able to analyse the causal relations between regional employment growth in Knowledge-Intensive Business Services (KIBS) and overall regional employment growth in Germany for the period 1999-2012. Our findings can be summarized in three main messages, one general and two more specific.

First, there are clear connections between KIBS and the rest of the regional economy in terms of employment growth. Growth in other industries can influence the expansion of KIBS and leads the feedback to the regional economy in the long-run. It follows, regions might experience a positive feedback loop for some years if either KIBS activities or activities in the rest of the economy are triggered by exogenous events, such as policy measures. Hence our results support the earlier arguments that KIBS should be made part of regional policy (Den Hertog, 2000; Muller and Zenker, 2001).

Second, further investigation of the feedbacks showed that the manufacturing sector benefits from growth in non-financial KIBS in the long-run, but not from growth in financial KIBS. In general, financial KIBS seem to have connections only with service industries, and their interactions with the overall regional growth seem to occur uniquely through their effect on, and influences from, the growth in other services. Insofar as the objective of regional policy is to enhance the manufacturing sector, and KIBS is supportive of these sectors, such policies should focus on non-financial KIBS rather than financial KIBS.

Third, the effects of growth in the rest of the economy, especially the other service industries, on financial KIBS seem to be strongest. That is, financial KIBS do not suffer from short-term negative interactions with the rest of the economy, and seem instead to feed back on the rest of the economy both in the short and in the long term, and at higher magnitude levels than the other KIBS. In bad times, such procyclical behaviour could backfire: in case of a negative shock to the economy, no matter whether the original shock hits financial KIBS or some other industries, the crisis can enter a vicious depressing circle. Thus, financial KIBS can be seen as accelerators in the regional economy as well in positive developments as in negative developments. In line with recent evidence (Borio et al., 2001; Bikker and Metzemakers, 2005; Pike and Pollard, 2010), financial services tend to have de-stabilizing effects on a sustained growth path of regions.

\section{References}

Agarwal, S. and Hauswald, R. (2010). Distance and private information in lending. Review of Financial Studies, 23: 2757-2788.

Arora, A. and Forman, C. (2007). Proximity and information technology outsourcing: How local are IT services markets? Journal of Management Information Systems, 24: 73-102. 
Bikker, J. A. and Metzemakers, P. A. (2005). Bank provisioning behaviour and procyclicality. Journal of International Financial Markets, Institutions and Money, 15: 141-157.

Binder, J. and Schwengler, B. (2006). Neuer Gebietszuschnitt der Arbeitsmarktregionen im Raum Berlin und Brandenburg: kritische überprüfung der bisher gültigen Arbeitsmarktregionen und Vorschläge für einen Neuzuschnitt. IAB-Forschungsbericht 2006-04, Institut für Arbeitsmarkt- und Berufsforschung (IAB).

Borio, C., Furfine, C. and Lowe, P. (2001). Procyclicality of the financial system and financial stability: Issues and policy options. BIS Papers chapters, 1: 1-57.

Bottazzi, G., CoAd, A., Jacoby, N. and Secchi, A. (2011). Corporate growth and industrial dynamics: Evidence from French manufacturing. Applied Economics, 43: 103-116.

-, Secchi, A. and Tamagni, F. (2014). Financial constraints and firm dynamics. Small Business Economics, 42: 99-116.

Brock, W. A. (1999). Scaling in economics: A reader's guide. Industrial and Corporate Change, 8: 409-446.

Broekel, T. and Binder, M. (2007). The regional dimension of knowledge transfers - a behavioral approach. Industry and Innovation, 14: 151-175.

Bryson, J. R., Daniels, P. W. and Warf, B. (2004). Service worlds: People, organisations and technologies. New York: Routledge.

Buerger, M., Broekel, T. and Coad, A. (2012). Regional dynamics of innovation: Investigating the co-evolution of patents, research and development (R\&D), and employment. Regional Studies, 46: 565-582.

Castaldi, C. (2009). The relative weight of manufacturing and services in Europe: An innovation perspective. Technological Forecasting and Social Change, 76: 709-722.

— and SAPIO, S. (2008). Growing like mushrooms? Sectoral evidence from four large European economies. Journal of Evolutionary Economics,18: 509-527.

Castellacci, F. (2008). Technological paradigms, regimes and trajectories: Manufacturing and service industries in a new taxonomy of sectoral patterns of innovation. Research Policy, 37: 978-994.

COAD, A. (2010). Exploring the processes of firm growth: Evidence from a Vector AutoRegression. Industrial and Corporate Change,19: 1677-1703.

— and Binder, M. (2014). Causal linkages between work and life satisfaction and their determinants in a structural VAR approach. Economics Letters, 124: 263-268. 
- and Broekel, T. (2012). Firm growth and productivity growth: Evidence from a panel VAR. Applied Economics, 44: 1251-1269.

-, Cowling, M. and Siepel, J. (2012). Growth processes of high-growth firms in the UK. Working Paper Series 12/10, NESTA.

Comon, P. (1994). Independent component analysis, a new concept? Signal processing, 36: $287-314$.

Consoli, D. and Elche-Hortelano, D. (2010). Variety in the knowledge base of Knowledge Intensive Business Services. Research Policy, 39: 1303-1310.

Corrocher, N. and Cusmano, L. (2014). The 'KIBS engine' of regional innovation systems: Empirical evidence from European regions. Regional Studies, 48: 1212-1226.

Coval, J. D. and Moskowitz, T. J. (1999). Home bias at home: Local equity preference in domestic portfolios. Journal of Finance, 54: 2045-2073.

- and - (2001). The geography of investment: Informed trading and asset prices. Journal of Political Economy, 109: 811-841.

Degryse, H. and Ongena, S. (2005). Distance, lending relationships, and competition. The Journal of Finance, 60: 231-266.

Demiralp, S. and Hoover, K. D. (2003). Searching for the causal structure of a vector autoregression. Oxford Bulletin of Economics and Statistics,65: 745-767.

Den Hertog, P. (2000). Knowledge-Intensive Business Services as co-producers of innovation. International Journal of Innovation Management, 4: 491-528.

Duschl, M. and Brenner, T. (2013a). Characteristics of regional industry-specific employment growth rates' distributions. Papers in Regional Science, 92: 249-270.

- and - (2013b). Growth dynamics in regional systems of technological activities - A SVAR approach. Working papers on innovation and space, Philipps University Marburg, Department of Geography.

European Commission (2009). Challenges for EU support to innovation in services. Commission Staff Working Document 1195, Innovation policy initiative PRO INNO Europe.

European Commission (2012). The smart guide to service innovation. Guidebook series "How to support sme policy from structural funds", European Commission's Enterprise and Industry Directorate-General. 
Fagiolo, G., Napoletano, M. and Roventini, A. (2008). Are output growth-rate distributions fat-tailed? Some evidence from OECD countries. Journal of Applied Econometrics, 23: 639-669.

Ferkingstad, E., Løland, A. and Wilhelmsen, M. (2011). Causal modeling and inference for electricity markets. Energy Economics, 33: 404-412.

Fixler, D. J. and Siegel, D. (1999). Outsourcing and productivity growth in services. Structural Change and Economic Dynamics, 10: 177-194.

Foray, D., David, P. A. and Hall, B. (2009). Smart specialisation - the concept. Knowledge Economists Policy Brief, 9: 25-29.

Grimshaw, D. and Miozzo, M. (2006). Institutional effects on the IT outsourcing market: Analysing clients, suppliers and staff transfer in Germany and the UK. Organization Studies, 27: $1229-1259$.

Groshen, E. L. and Potter, S. (2003). Has structural change contributed to a jobless recovery? Current Issues in Economics and Finance, 9: 1-7.

Hashimzade, N. and Thornton, M. A. (2013). Handbook of Research Methods and Applications in Empirical Macroeconomics. Cheltenham: Edward Elgar Publishing.

Henderson, J. V. and OnO, Y. (2008). Where do manufacturing firms locate their headquarters? Journal of Urban Economics, 63: 431-450.

Herstad, S. J. and Ebersberger, B. (2014). Urban agglomerations, knowledge-intensive services and innovation: Establishing the core connections. Entrepreneurship $\&$ Regional Development, 26: 211-233.

Heshmati, A. (2003). Productivity growth, efficiency and outsourcing in manufacturing and service industries. Journal of Economic Surveys,17: 79-112.

Hyvärinen, A. and OJA, E. (2000). Independent component analysis: Algorithms and applications. Neural networks, 13: 411-430.

-, Shimizu, S. and Hoyer, P. O. (2008). Causal modelling combining instantaneous and lagged effects: An identifiable model based on non-Gaussianity. In Proceedings of the 25th International Conference on Machine Learning, ACM, pp. 424-431.

Jacobs, W., Koster, H. R. and van Oort, F. (2014). Co-agglomeration of KnowledgeIntensive Business Services and multinational enterprises. Journal of Economic Geography, 14: 443-475. 
Janssen, M. (2014). A holistic view on service innovation: Four approaches for developing systemic policy mixes. Paper presented at the DRUID society conference 2014, CBS, Copenhagen, June 16-18.

Jensen, M. B., Johnson, B., Lorenz, E. and Lundvall, B. Å. (2007). Forms of knowledge and modes of innovation. Research policy, 36: 680-693.

Keeble, D. and Nachum, L. (2002). Why do business service firms cluster? Small consultancies, clustering and decentralization in London and Southern England. Transactions of the Institute of British Geographers, pp. 67-90.

Klagge, B. and Martin, R. (2005). Decentralized versus centralized financial systems: Is there a case for local capital markets? Journal of Economic Geography, 5: 387-421.

Koch, A. and Stahlecker, T. (2006). Regional innovation systems and the foundation of Knowledge-Intensive Business Services. A comparative study in Bremen, Munich, and Stuttgart, Germany. European Planning Studies, 14: 123-146.

Lee, R., Clark, G. L., Pollard, J. and Leyshon, A. (2009). The remit of financial geography - before and after the crisis. Journal of Economic Geography, 9: 723-747.

Leiponen, A. (2001). Knowledge services in the innovation system. Helsinki: Taloustieto.

Luetkepohl, H. (2009). Econometric analysis with vector autoregressive models. In D. A. Belsley and E. J. Kontoghiorghes (eds.), Handbook of Computational Econometrics, John Wiley \& Sons, Ltd, pp. 281-319.

Lütkepohl, H. (2001). Vector autoregressions. In B. Baltagi (ed.), A Companion to Theoretical Econometrics, Wiley Online Library, pp. 678-699.

McCann, P. and Ortega-Argilés, R. (2013). Smart specialization, regional growth and applications to European Union cohesion policy. Regional Studies, 49: 1291-1302.

Meliciani, V. and Savona, M. (2015). The determinants of regional specialisation in business services: Agglomeration economies, vertical linkages and innovation. Journal of Economic Geography, 15: 387-416.

Merino, F. and Rubalcaba, L. (2013). Are knowledge-intensive services highly concentrated? Evidence from European regions. Tijdschrift voor Economische en Sociale Geografie, 104: 215232 .

Miles, I., Kastrinos, N., Bilderbeek, R., den Hertog, P., Flanagan, K., Huntink, W. and Bouman, M. (1995). Knowledge-Intensive Business Services: Users, carriers and sources of innovation. EIMS Publication 15, European Innovation Monitoring System-European Commission DGXII. 
Miozzo, M. and Grimshaw, D. (2005). Modularity and innovation in Knowledge-Intensive Business Services: IT outsourcing in Germany and the UK. Research Policy, 34: 1419-1439.

Moneta, A., Entner, D., Hoyer, P. O. and Coad, A. (2013). Causal inference by independent component analysis: Theory and applications. Oxford Bulletin of Economics and Statistics, 75: 705-730.

Moretti, E. (2010). Local multipliers. The American Economic Review, Papers and Proceedings of the 122nd Annual Meeting of the AEA, 100: 373-377.

- and Thulin, P. (2013). Local multipliers and human capital in the United States and Sweden. Industrial and Corporate Change, 22: 339-362.

Muller, E. and Doloreux, D. (2009). What we should know about knowledge-intensive business services. Technology in Society, 31: 64-72.

- and Zenker, A. (2001). Business services as actors of knowledge transformation: The role of KIBS in regional and national innovation systems. Research policy, 30: 1501-1516.

Neffke, F. and Henning, M. (2013). Skill relatedness and firm diversification. Strategic Management Journal, 34: 297-316.

OnO, Y. (2003). Outsourcing business services and the role of central administrative offices. Journal of Urban Economics, 53: 377-395.

Petersen, M. A. and Rajan, R. G. (2002). Does distance still matter? The information revolution in small business lending. The Journal of Finance, 57: 2533.

Pike, A. and Pollard, J. (2010). Economic geographies of financialization. Economic Geography, 86: 29-51.

Rubalcaba, L. (2011). Business services in European economic growth. Strategic Direction, 28.

-, Michel, S., Sundbo, J., Brown, S. W. and Reynoso, J. (2012). Shaping, organizing, and rethinking service innovation: A multidimensional framework. Journal of Service Management, 5: 696-715.

SARgent, T. J. (1979). Estimating vector autoregressions using methods not based on explicit economic theories. Federal Reserve Bank of Minneapolis Quarterly Review, 3: 272 - 279.

Sassen, S. (1991). The Global City: New York, London, Tokyo. Princeton: Princeton University Press.

Shimizu, S., Hoyer, P. O., Hyvärinen, A. and Kerminen, A. (2006). A linear non-Gaussian acyclic model for causal discovery. The Journal of Machine Learning Research, 7: 2003-2030. 
Sims, C. A. (1986). Are forecasting models usable for policy analysis? Federal Reserve Bank of Minneapolis Quarterly Review, 10: 2-16.

Stanley, M. H., Amaral, L. A., Buldyrev, S. V., Havlin, S., Leschhorn, H., Maass, P., Salinger, M. A. and Stanley, H. E. (1996). Scaling behaviour in the growth of companies. Nature,379: 804-806.

Stock, J. H. and WAtson, M. W. (2001). Vector autoregressions. Journal of Economic perspectives, 15: 101-115.

Stolz, S. and Wedow, M. (2011). Banks' regulatory capital buffer and the business cycle: Evidence for Germany. Journal of Financial Stability, 7: 98-110.

Strambach, S. (2008). Knowledge-Intensive Business Services (KIBS) as drivers of multilevel knowledge dynamics. International Journal of Services Technology and Management, 10: 152174 .

Wernerheim, C. M. and Sharpe, C. (2003). 'High order' producer services in metropolitan Canada: How footloose are they? Regional Studies, 37: 469-490.

Wold, H. (1938). A study in the analysis of stationary time series. Uppsala: Almqvist \& Wiksell.

Wood, P. (2006). Urban development and Knowledge-Intensive Business Services: Too many unanswered questions? Growth and Change, 37:335-361. 